\title{
Needle-knife incisional treatment of refractory esophagic caustic stenosis
}

A 44-year-old man accidentally ingested sodium hydroxide solution in December 2007. Endoscopic evaluation in the emergency room revealed grade III esophagitis and extensive gastric ulcerations. After 2 weeks, the patient had considerable dysphagia in relation to solid foods. The regenerating esophageal mucosa had two $8-\mathrm{mm}$ diameter strictures, at 20 and $25 \mathrm{~cm}$ from the central incisor, and there was antral scarring with a pyloric stricture. After multiple attempts at stenosis dilation (Savary-Gilliard and through-the-scope techniques) and betamethasone dipropionate injections ( $4 \mathrm{mg}$ ), there was resolution of the pyloric and proximal esophageal strictures but monthly interventions continued to be required for the refractory esophageal stricture at $25 \mathrm{~cm}$ from the incisors. In January 2010, a Polyflex esophageal stent (Boston Scientific, Natick, Massachusetts, USA; inner diameter 16-20 mm, length $90 \mathrm{~mm}$ ) was placed but it was removed 3 months later. Prosthesis removal was difficult because of the presence of granulation tissue at both ends. After prosthesis removal, 9and 11-mm diameter strictures were observed at 20 and $25 \mathrm{~cm}$ from the incisors and the patient attended two additional sessions of dilation and betamethasone dipropionate injections, with resolution of the distal stricture. The fibrotic proximal stricture ( $\bullet$ Fig. 1 ) was then submitted to needle-knife incisional treatment: several small cuts (Endocut mode, ICC200, ERBE Elektromedizin GmbH, Tubingen, Germany) parallel to the longitudinal axis of the esophagus were made, resulting in widening of the lumen and easy passage of the scope ( $\bullet$ Fig. 2). There were no complications either during or after the procedure. Endoscopic reassessment 1 and 6 months later ( Fig. 3 ) showed minor fibrotic retraction. At the 1-year followup, no further therapeutic interventions were required as the patient remained free of dysphagia.

Benign esophageal strictures are often difficult to treat and the currently practiced dilation techniques are equally effective [1]. Treatment with needle-knife incision has been described [1-3] for benign esophageal strictures as a fast, easy, and

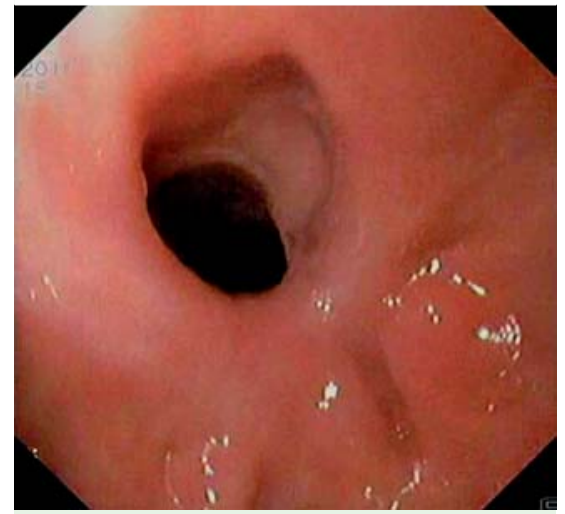

Fig. 1 Fibrotic esophageal stricture before incisional treatment, in a 44-year-old man who accidentally ingested sodium hydroxide solution.

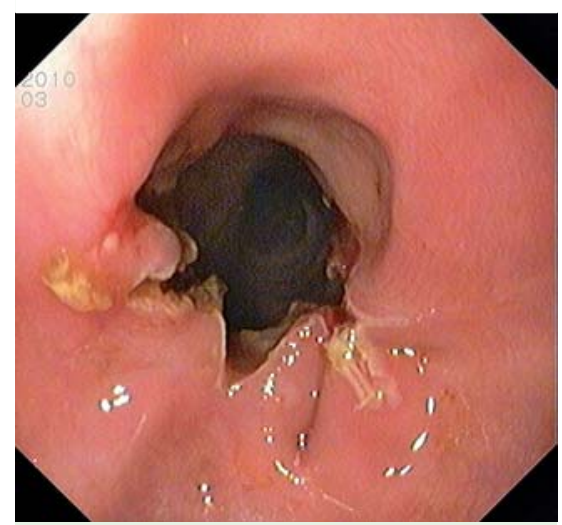

Fig. 2 The widened lumen of the stricture after incisional treatment.

safe alternative to other methods, with particularly good results in patients with fibrotic strictures such as in the case described here.

\section{Endoscopy_UCTN_Code_TTT_1AO_2AN}

\section{Competing interests: None}

M. Canhoto, B. Arroja, F. Silva, C. Gonçalves, I. Cotrim, H. Vasconcelos Department of Gastroenterology, Hospital de Santo André E. P.E., Leiria, Portugal

\section{References}

1 Hordijk ML, van Hooft JE, Hansen BE et al. A randomized comparison of electrocautery incision with Savary bougienage for relief of anastomotic gastroesophageal strictures. Gastrointest Endosc 2009; 70: 849-855

2 Brandimarte G, Tursi A. Endoscopic treatment of benign anastomotic esophageal ste-
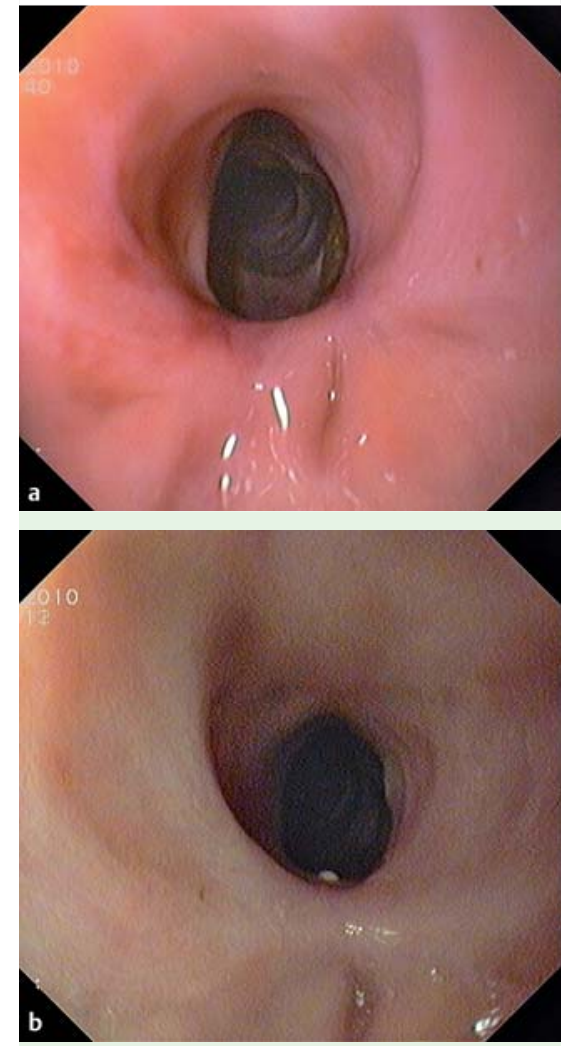

Fig. 3 Follow-up images at 1 month (a) and 6 months (b) after the procedure.

nosis with electrocautery. Endoscopy 2002; 34: 399- 401

3 Hordijk ML, Siersema PD, Tilanus HW et al. Electrocautery therapy for refractory anastomotic strictures of the esophagus. Gastrointest Endosc 2006; 63: 157-163

Bibliography

DOI 10.1055/s-0030-1256941

Endoscopy 2011; 43: E386

(c) Georg Thieme Verlag KG Stuttgart · New York . ISSN 0013-726X

Corresponding author

\section{Canhoto}

Hospital de Santo André, E.P.E.

Serviço de Gastrenterologia

Rua das Olhalvas, Pousos

2410197 Leiria

Portugal

Fax: +351-244-817080

manela_vc@yahoo.com 